\title{
Induction of the chemokine interferon- $\gamma$-inducible protein-10 in human pancreatic islets during enterovirus infection
}

\author{
A.-K. Berg • O. Korsgren • G. Frisk
}

Received: 18 April 2006 / Accepted: 28 July 2006 / Published online: 13 September 2006

(C) Springer-Verlag 2006

\begin{abstract}
Aims/hypothesis Enterovirus infections have long been suspected to be environmental factors that may cause type 1 diabetes, but the pathways leading from infection to beta cell destruction are still unknown. We therefore examined whether enterovirus infection of human islets leads to upregulation of interferon- $\gamma$-inducible protein (IP-10, now known as chemokine [C-X-C motif] ligand 10 [CXCL10]), a chemokine important for the induction of insulitis. Methods Isolated human islets were infected with three different strains of Coxsackie B4 virus. IP-10 expression and secretion from the infected human islets were then measured using RT-PCR and ELISA at several time points. Results IP-10 was clearly upregulated in and secreted from human islets during enterovirus infection. This was demonstrated with three different strains of Coxsackie B4 virus, two of which are lytic to islets and one which is non-lytic and can establish a persistent infection in human islets. Conclusions/interpretation We propose that enterovirusinduced upregulation of IP-10 during infection of the islets in vivo is the first step towards destructive insulitis. Our findings support the idea that enterovirus infection triggers
\end{abstract}

Electronic supplementary material Supplementary material is available in the online version of this article at http://dx.doi.org/ $10.1007 / \mathrm{s} 00125-006-0429-7$ and is accessible to authorised users.

A.-K. Berg • G. Frisk $(\bowtie)$

Department of Women's and Children's Health,

Uppsala University,

Akademiska Sjukhuset, ing 95/96,

SE-751 85 Uppsala, Sweden

e-mail: Gun.Frisk@kbh.uu.se

\section{O. Korsgren}

Department of Oncology, Radiology and Clinical Immunology,

Uppsala University,

Uppsala, Sweden immune-mediated beta cell destruction, and for the first time suggest a possible mechanism behind enterovirusinduced diabetes.

Keywords Chemokines · Enterovirus · Human islets . IP-10 · Picornavirus · Type 1 diabetes

\author{
Abbreviations \\ CBV Coxsackie B Virus \\ CXCR3 chemokine (C-X-C motif) receptor 3 \\ GMK Green Monkey Kidney \\ IP-10 interferon- $\gamma$-inducible protein-10 (now known as \\ chemokine $[\mathrm{C}-\mathrm{X}-\mathrm{C}$ motif] ligand 10 \\ [CXCL10]) \\ $\mathrm{TCID}_{50}$ tissue culture infectious dose-50 \\ p.i. post inoculation \\ UV ultraviolet
}

\section{Introduction}

Enterovirus infection is believed to be an environmental factor in type 1 diabetes pathogenesis, but the sequence of events from virus infection to beta cell destruction remains unclear. Recent evidence suggests that viral induction of cytokines and chemokines promoting insulitis could be an important link between virus infections and type 1 diabetes [1].

Enteroviruses belong to the picornavirus family of small non-enveloped RNA viruses. The enterovirus group includes the Coxsackie A and Coxsackie B (CBV) viruses, echoviruses and polioviruses, as well as several numbered enteroviruses. Their normal route of infection is via the gastrointestinal tract and they frequently cause asymptom- 
atic infections or mild febrile illness associated with upper respiratory tract symptoms. In some cases, however, the virus can spread to secondary sites of replication in different organs and cause more severe diseases such as poliomyelitis, meningitis and myocarditis [2].

Enterovirus infections with different serotypes have frequently been detected in association with the appearance of autoantibodies in subjects with a high genetic risk for type 1 diabetes and at the clinical onset of type 1 diabetes in various studies [3-10]. This suggests not only that enteroviruses are involved in type 1 diabetes pathogenesis, but also that individual strains of many different serotypes may share diabetogenic properties. Enterovirus RNA has also been detected by in situ hybridisation solely in the pancreatic islets of some type 1 diabetes patients in a post mortem study [11], clearly indicating that islet cells can be infected by these viruses. There are also some cases where enterovirus isolates from newly diagnosed type 1 diabetes patients have been capable of inducing hyperglycaemia in mice $[12,13]$.

The properties that may enable a virus to cause or precipitate type 1 diabetes have not yet been determined, but several hypotheses have been suggested. A virus infection of the islets might cause direct beta cell damage through virus-induced cytolysis. This is the outcome with most enterovirus strains when human islets are infected in culture $[14,15]$. Under certain conditions, enterovirus infections of islet cells can also proceed without cell lysis in vitro $[16,17]$. This suggests that some enteroviruses might establish persistent infections in islets in vivo. In the long-term, enteroviral persistence in beta cells might impair beta cell function or increase the immunogenicity of beta cell antigens. In addition, both lytic and non-lytic enterovirus infections might promote beta cell damage by inducing cytotoxic proinflammatory cytokines and chemokine expression in the islets $[18,19]$. An enterovirus infection might thus stimulate immune cell infiltration of the islets in vivo, thereby facilitating immune-mediated beta cell damage.

The chemokine interferon- $\gamma$-inducible protein (IP-10), now known as chemokine $(\mathrm{C}-\mathrm{X}-\mathrm{C}$ motif) ligand 10 (CXCL10), acts via a single receptor, chemokine (C-X-C motif) receptor 3 (CXCR3), attracting activated type 1 T-cells, natural killer cells and monocytes [20]. This chemokine has been implicated in several immunoinflammatory and autoimmune diseases. For example, serum concentrations of IP-10 have been found to be elevated in type 1 diabetes patients at onset $[21,22]$ and in autoantibody-positive relatives compared with healthy control subjects [22]. Recent evidence from the rat insulin promotor-lymphocytic choriomeningitis virus mouse model of virus-induced diabetes supports the hypothesis that virus-induced production of chemokines in the pancreatic islets could be involved in inducing insulitis and T-cellmediated destruction of beta cells in type 1 diabetes. The CXCR3-chemokine IP-10 (CXCL10) was found to be the key mediator in this process $[23,24]$.

The aim of the present study was to measure the expression and secretion of IP-10 from cultured human pancreatic islets before and after infection with enterovirus. The effects of enterovirus infection on human islets in culture have been found to differ depending on the infecting virus strain [14]. This study therefore compared islets infected with three different strains of CBV-4. All three virus strains (V89 4557, VD2921 and E2) have previously been used for the study of virus replication in human islets, and their effects range from no islet destruction (VD2921) to severe islet destruction within a week of infection (V89 4557 and E2) [14, 17].

\section{Materials and methods}

Cell culture

Human pancreata were procured from heart-beating organ donors at transplantation units in Sweden, Norway, Finland and Denmark. The pancreatic islets were then isolated in Uppsala, Sweden, by an automated method [25] and cultured in $90-\mathrm{mm}$ dishes for 3 to 7 days in $10 \mathrm{ml}$ RPMI supplemented with $10 \%$ human serum, before the experiments were performed. Islets were obtained from 20 different donors, nine women and 11 men with a mean age of $55 \pm 10$ (range 30-74) years and a mean BMI of $26 \pm 6$ (range $21-46) \mathrm{kg} / \mathrm{m}^{2}$. The mean ischaemia time before islet isolation was $10 \pm 4$ (range $3-16$ ) h. As a quality control, the insulin responsiveness of islets from 12 donors was assessed by glucose challenge using a dynamic perifusion system, as previously described [18]. The mean stimulation index, calculated as the ratio of the insulin released during high glucose to the insulin released during low glucose, was $14 \pm 12$ (range $3-36$ ). For the virus infections, islets were cultured in numbers of 50 to 300 per well in nonattach six-well plates in RPMI supplemented with $10 \%$ fetal bovine serum. Each experiment comprised virusinfected islets and uninfected control islets from the same donor. Green Monkey Kidney (GMK) cells were used for tissue culture infectious dose-50 $\left(\mathrm{TCID}_{50}\right)$ titrations and were cultured in 96-well culture plates (Nunc) in Eagle's Minimum Essential Medium (SVA, Uppsala, Sweden), supplemented with $10 \%$ fetal bovine serum (Hyclone, Logan, UT, USA). This study was approved by the ethics committee of the Medical Faculty at Uppsala University. Written informed consent was obtained from all donors or their next of kin. 
Virus inoculations

Three CBV-4 strains were used to infect the isolated human islets. Two of the strains were originally plaque-purified from isolates from aseptic meningitis patients (VD2921, V89 4557). These two virus strains have previously been used to study the frequency of infections with different CBV-4 strains in type 1 diabetic patients [26, 27], as well as to study the effects of CBV-4 infection on isolated human islets [14]. The VD2921 strain causes a non-lytic infection in human islet cells in vitro and does not affect beta cell function up to 7 days post inoculation (p.i.) [17]. The V89 4557 strain causes a lytic infection in human islets in vitro and impairs the glucose-stimulated insulin response of beta cells 3 to 5 days p.i. [14]. The third CBV-4 strain, the E2 strain, was also originally plaque-purified from a patient with generalised Coxsackie virus infection and has been shown to infect islet cells in mice [28]. This strain also causes a lytic infection in human islets, but the degree of damage is less severe than with the V89 4557 strain [14]. Virus $\left(10^{4}-10^{5} \mathrm{TCID}_{50}\right.$ in $\left.0.2 \mathrm{ml}\right)$ was added to the islets together with $1 \mathrm{ml}$ RPMI culture medium containing $5.5 \mathrm{mmol} / 1$ glucose (SVA) and supplemented with L-glutamine and $10 \%$ fetal bovine serum. Islets to be used as uninfected controls were incubated with $1 \mathrm{ml}$ of culture medium without virus. After incubation for $1 \mathrm{~h}$ at $37^{\circ} \mathrm{C}$, $2 \mathrm{ml}$ of culture medium were added and $0.4 \mathrm{ml}$ samples of the culture medium were withdrawn from infected and uninfected islet cultures. Samples $(0.4 \mathrm{ml})$ of culture medium were collected every day for virus titrations and measurements of IP-10 for the duration of the experiments.

Exposure of islets to inactivated virus

Virus suspensions of CBV-4 VD2921 and CBV-4 V89 4557 were inactivated by exposure to ultraviolet (UV) light for $60 \mathrm{~min}$ or by incubation at $56^{\circ} \mathrm{C}$ for $60 \mathrm{~min}$. Groups of islets were then inoculated, as described above, with the heat- or UV-inactivated virus. As controls, islets were inoculated with non-treated virus and some were left uninfected. Islets and culture medium samples were collected on day 0 , day 1 and day 3 for IP-10 measurements and virus titrations.

Virus titrations

Quantification of virus was performed by $\mathrm{TCID}_{50}$ titrations of the samples of culture medium collected from infected islet cell cultures on days $0,1,3$ and 6 p.i. Briefly, the medium samples were diluted stepwise (from $10^{-1}$ to $10^{-6}$ ) and each dilution was added in triplicate to GMK cells in 96-well plates. After 7 days, the appearance of typical enterovirus-induced cytopathic effects on the GMK cells were observed using a light microscope. The $\mathrm{TCID}_{50}$-titre for each unknown sample was determined as the reciprocal of the highest dilution of the sample able to induce cytopathic effects in $50 \%$ of inoculated GMK cultures.

\section{IP-10 and beta-actin mRNA detection by RT-PCR}

We collected 50 islets from uninfected or infected cultures for RNA isolation on days $0,1,2$ and 4 p.i. The islets were first washed in PBS and then frozen in $30 \mu \mathrm{l}$ RNA later (Qiagen, Hilden, Germany) at $-70^{\circ} \mathrm{C}$. Total RNA was extracted by RNeasy mini kit (Qiagen). The cDNA was prepared from $0.5 \mu$ l of RNA template in a total volume of $20 \mu \mathrm{l}$, using oligo-(dT) $)_{12-18}$ primers (Invitrogen, Carlsbad, CA, USA) and Sensiscript cDNA kit (Qiagen). The cDNA reaction was carried out at $42^{\circ} \mathrm{C}$ for $1 \mathrm{~h}$. PCR was performed on $2 \mu \mathrm{l}$ of cDNA using a PCR kit (HotStarTaq; Qiagen). Separate PCR reactions were used to detect expression of human $I P-10$ and of the control gene human beta-actin. The specific primers (Operon Biotechnologies, Cologne, Germany), lengths of amplified PCR products and annealing temperatures are listed in Table 1 of the Electronic supplementary material. The human beta-actin primers were designed using the on-line Primer-3 software program [29]. The PCR cycling conditions were $95^{\circ} \mathrm{C}$ for $15 \mathrm{~min}, 33$ cycles of $94^{\circ} \mathrm{C}$ for $45 \mathrm{~s}, 53^{\circ} \mathrm{C}$ or $55^{\circ} \mathrm{C}$ for $45 \mathrm{~s}$, $72^{\circ} \mathrm{C}$ for $1 \mathrm{~min}$ followed by a final extension at $72^{\circ} \mathrm{C}$ for $10 \mathrm{~min}$. The amplified PCR fragments were visualised on a $1.4 \%$ agarose gel containing ethidium bromide.

\section{IP-10 protein detection by ELISA}

We collected 50 islets from uninfected or infected cultures for IP-10 protein measurements on days $0,1,3,4$ and 6 p.i. The islets were washed, resuspended in $300 \mu$ PBS and stored at $-20^{\circ} \mathrm{C}$. Before the IP- 10 protein measurements, the islets were exposed to UV-light for $30 \mathrm{~min}$ to inactivate virus, and then sonicated. Samples of culture medium collected from the same cultures at the indicated time points were also exposed to UV-light before the measurements of IP-10 protein. Human IP-10 protein was measured by ELISA (Human IP-10 Cytoscreen; Biosource, Nivelles, Belgium) with a lowest detection limit of $<2.0 \mathrm{pg} / \mathrm{ml}$.

\section{Statistical analysis}

IP-10 protein content as well as IP-10 secretion from virusinfected islets were compared with matched uninfected islets using Wilcoxon signed ranks test. The Friedman test was used to compare the groups in the UV-inactivation experiments. A $p$ value of less than 0.05 was considered statistically significant. 


\section{Results}

Virus replication

The mean changes in virus titres from day 0 to days 1,3 or 4 to 6 are shown in Tables 1 and 2. In some cases the virus titres decreased slightly from day 0 to day 1 , but titres increased again until days 3 and 6 in these experiments, demonstrating virus replication. There was no virus replication in islets inoculated with the UV-treated VD2921 strain or with the heat-inactivated virus strains. The UV-treated V89 4557 strain, however, was not completely inactivated, despite the fact that the UVtreatment had reduced the virus titres in the inoculum of the V89 4557 strain from $10^{4} \mathrm{TCID}_{50}$ to undetectable levels. The mean virus titres of the UV-treated V89 4557 were $0 \log \mathrm{TCID}_{50}$ on day 0 and increased to $1.4 \log \mathrm{TCID}_{50}$ on day $3(n=4)$.

IP-10 and beta-actin mRNA expression in virus-infected islets

Increased amounts of $I P-10$ mRNA were detected by RTPCR on days 1 and 2 after infection in virus-infected human islets compared with uninfected control islets with all three virus strains (Fig. 1; E2 strain $(n=1)$ not shown). Islets from six donors were used for mRNA analysis and only one donor showed a different response (donor H590). Islets from this donor (H590) expressed IP-10 mRNA in the uninfected control islets as well as in the infected islets on day 1 . The beta-actin mRNA levels did not change after virus infection (Fig. 1). Analysis of IP-10 mRNA expression on day 4 was performed in one experiment (donor H586, VD2921), and showed that strong upregulation of $I P-10$ in virus-infected compared with uninfected islets also occurred on day 4.
IP-10 protein content in virus-infected islets

Measurements of IP-10 protein confirmed that IP-10 was upregulated in virus-infected human islets compared with the uninfected controls (Table 1). The IP-10 concentrations were higher in V89 4557-infected islets on days 1 and 3 after infection $(p<0.05$, Wilcoxon signed ranks test) than in the controls. In VD2921-infected islets the difference was not statistically significant compared with uninfected islets until day $3(p<0.05)$.

IP-10 protein release from virus-infected human islets

IP-10 protein was released into the culture medium as early as the first $24 \mathrm{~h}$ of infection with the lytic V89 4557 strain $(p<0.05)$ (Table 2). The islets infected with the non-lytic VD2921 strain showed a tendency toward increased IP-10 release on day 1 compared with controls, but this did not reach statistical significance $(p=0.06)$. Measurements performed on days 3 and 4 to 6 , however, showed that both virus strains clearly induced a release of IP-10 from the islets $(p<0.05)$ (Table 2).

IP-10 induction by inactivated virus

Heat-inactivated virus did not induce any release $(n=3)$ or expression $(n=2)$ of IP-10 in islets on day 1 or day 3 (data not shown). The UV-inactivated VD2921 strain, which did not replicate at all, also failed to induce IP-10 expression or release (Table 3). The UV-treated V89 4557 strain, which was not completely inactivated, induced some expression and release of IP-10 from islets on day 3 , but to a significantly lower degree than untreated virus $(p<0.05)$ (Table 3).

\section{Discussion}

CBV-4 infection of isolated human pancreatic islet cells induced an upregulation of $I P-10$ mRNA and IP-10 protein

Table 1 Increases in IP-10 protein content in islets from day 0 to day 1 or day 3

\begin{tabular}{llllll}
\hline & & Increase in IP-10 in islets (pg/50 islets) & Wilcoxon signed ranks test & Mean virus titre change from day 0 (logTCID $\left.)_{50}\right)$ \\
\hline & $n$ & Uninfected & V89 4557 & & \\
Day 1 & 8 & $0(0-62)$ & $11(0-82)^{*}$ & $p=0.02$ & 0.5 \\
Day 3 & 6 & $1(0-4)$ & $160(5-280)^{*}$ & $p=0.03$ & 1.4 \\
& & Uninfected & VD2921 & & -0.4 \\
Day 1 & 7 & $0(0-6)$ & $6(0-97)$ & NS $(p=0.09)$ & 0.8 \\
Day 3 & 7 & $1(0-21)$ & $107(5-186)^{*}$ & $p=0.02$ & \\
\hline
\end{tabular}

Results are presented as medians (range) from islets infected with the V89 4557 or VD2921 strain and from uninfected islets from the same donors. Mean virus titre changes from day 0 are also shown.

$*_{p}<0.05$, Wilcoxon signed ranks test 
Table 2 Increase in IP-10 content in the culture medium from islets infected with the V89 4557 or VD2921 strain and from uninfected islets from the same donors

\begin{tabular}{|c|c|c|c|c|c|}
\hline & & \multicolumn{2}{|c|}{ Increase of IP-10 in medium ( $\mathrm{pg} / 50$ islets) } & \multirow[t]{2}{*}{ Wilcoxon signed ranks test } & \multirow{2}{*}{$\begin{array}{l}\text { Mean virus titre change from day } 0 \\
\left(\log \mathrm{TCID}_{50}\right)\end{array}$} \\
\hline & $n$ & Uninfected & V89 4557 & & \\
\hline Day 1 & 15 & $2(0-26)$ & $6(0-494) *$ & $p=0.01$ & 0.6 \\
\hline Day 3 & 13 & $6(0-22)$ & $431(8-1232)^{* *}$ & $p=0.001$ & 1.6 \\
\hline \multirow[t]{2}{*}{ Day 4-6 } & 5 & $12(1-18)$ & $787(32-1699)^{*}$ & $p=0.04$ & 1.7 \\
\hline & & Uninfected & VD2921 & & \\
\hline Day 1 & 9 & $1(0-13)$ & $5(0-74)$ & NS $(p=0.06)$ & -0.4 \\
\hline Day 3 & 10 & $5(0-42)$ & $399(5-1704)^{*}$ & $p=0.01$ & 0.9 \\
\hline Day 4-6 & 5 & $16(0-190)$ & $222(10-498)^{*}$ & $p=0.04$ & 1.0 \\
\hline
\end{tabular}

IP-10 protein concentrations were measured on days $0,1,3$ and 4-6 after infection. The increase of IP-10 from day 0 to day 1, day 3 or days $4-6$ are presented as medians (range). Virus replication is presented as the mean $\mathrm{TCID}_{50}$ titre change.

${ }^{*} p<0.05$, Wilcoxon signed ranks test

$* * p<0.01$, Wilcoxon signed ranks test

expression, leading to secretion of IP-10 into the culture medium. Virus that had been completely inactivated by heat or UV-treatment was unable to induce IP-10, suggesting a mechanism of induction dependent on virus replication.

All three CBV-4 strains were capable of inducing IP-10 mRNA expression one day after infection and IP-10 protein production was confirmed in VD2921 and V89 4557infected islets. Virus-induced release of IP-10 was detectable from day 1 , but was most evident at the later time points (days 3-6). Some variation was seen between experiments regarding the level and timing of IP-10 induction after virus inoculation, but this was probably due to donor differences. The genetic background and the cause of death of the donor may have affected both the degree of IP-10 response and the susceptibility to virus infection. In our study, $I P-10$ was shown to be upregulated at the mRNA level up to 4 days after virus infection in human islets, which can be compared with the transient induction up to 24 or $48 \mathrm{~h}$ that has been found in other cell culture studies $[30,31]$. The comparatively long upregula- tion in human islets may be explained by the growth pattern of the cells, i.e. the fact that even in vitro not all cells of an islet are exposed to the virus at once. If new cells are being gradually infected, IP-10 induction in new cells may also be gradual. If only a proportion of the islet cells are infected at one time, this could also explain why virus titre increases are sometimes difficult to detect in the culture medium from islet cultures.

In the present study we showed that several strains of CBV-4, the VD2921 strain, which does not destroy islets [17], as well as the islet-cell-lytic strains E2 and V89 4557 [14], share the ability to induce IP-10. A previous microarray study of isolated human islets has shown an upregulation of $I P-10$, among other chemokines, at the mRNA level $48 \mathrm{~h}$ after inoculation with the prototype strain of CBV-5 [19], a finding that is in agreement with ours. In our study, we also extended the measurement of IP-10 expression to several time points and found that virusinduced IP-10 can be detected in islets from day 1 to day 4 post infection. In addition, we showed that IP-10 protein is

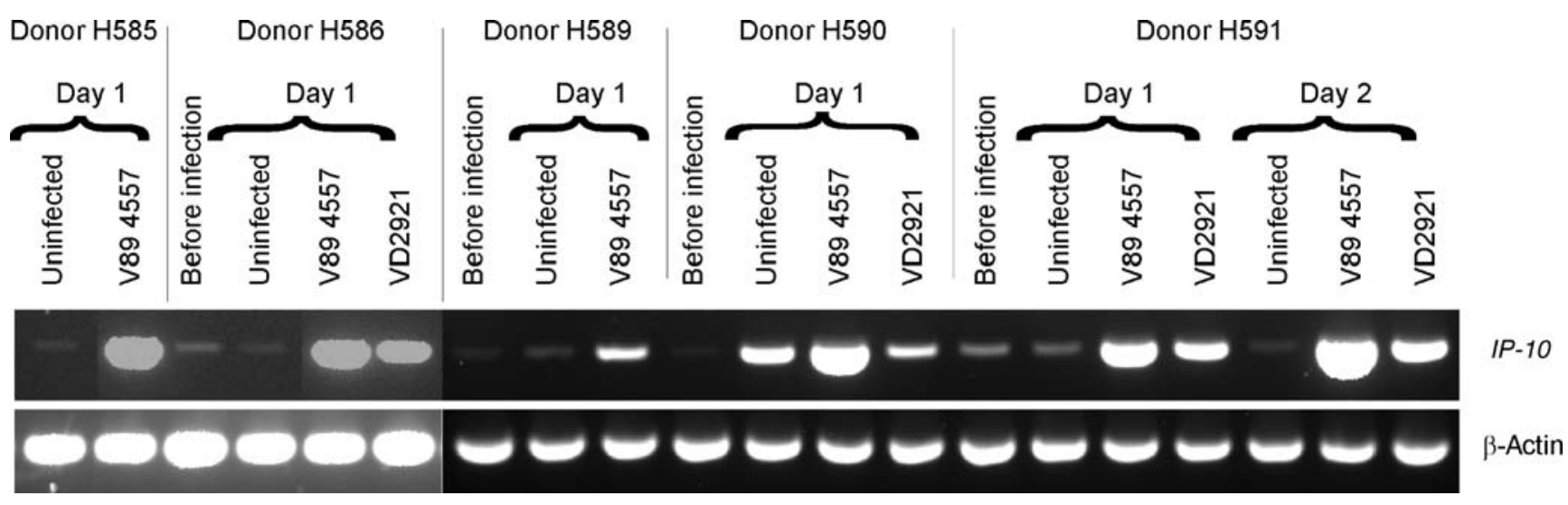

Fig. 1 Expression of $I P-10$ and beta-actin mRNA before and after CBV-4 infection of human islets. Islets from five donors were infected with the VD2921 strain or the V89 4557 strain or were left uninfected.
RT-PCR analysis was performed before infection (day 0), $24 \mathrm{~h}$ after infection (day 1) and $48 \mathrm{~h}$ after infection (day 2) 
Table 3 Increase in IP-10 content in culture medium from virus-infected islets, islets inoculated with UV-treated virus and islets left uninfected

Increase of IP-10 in medium (pg/50 islets)

Friedman test

\begin{tabular}{llllll}
\hline & $n$ & Uninfected & V89 4557 & V89 4557-UV & \\
Day 1 & 4 & $0(0-0)$ & $7(0-20)$ & $0(0-251)$ & NS \\
Day 3 & 4 & $0(0-6)$ & $516(365-1232)^{*}$ & $126(6-833)$ & $p=0.04$ \\
& & Uninfected & VD2921 & VD2921-UV & \\
Day 1 & 3 & $0(0-0)$ & $1(0-31)$ & $0(0-1)$ & NS \\
Day 3 & 4 & $0(0-6)$ & $1022(7-1704)^{*}$ & $1(0-19)$ & $p=0.03$ \\
\hline
\end{tabular}

The IP-10 increase was calculated from day 0 to day 1 or day 3 . Results are presented as medians (range).

${ }^{*} p<0.05$ for difference compared with all other groups, Friedman test

synthesised and secreted from the islets. It was important to verify this, because, in other cell systems, picornaviruses are known to shut off host cell (cap-dependent) translation in the infected cell [32]. There is also evidence that enteroviral proteins $2 \mathrm{~B}$ and $3 \mathrm{~A}$ can block the secretion of certain proteins from the infected cell [33-35]. The results from the UV-inactivation experiments suggest that the mechanism of induction of IP-10 in islets is dependent on virus replication. We clearly showed that UV-inactivated virus failed to induce the same IP-10 response in islets as untreated virus. It has been suggested that intracellular recognition of double-stranded RNA, which is a product formed during enterovirus replication, provides a strong signal for chemokine production [31].

Although the cell type in the human islets responsible for IP-10 production during enterovirus infection has not been identified, it is conceivable that beta cells as well as other islet cell types targeted by the virus contribute to this process. Rat beta cells [36] have been shown to produce IP-10 after exposure to cytokines and many cell types, including primary human airway epithelial cells [31] and primary murine astrocytes [30], respond to picornavirus infection by producing IP-10. Based on our observation that replication-incompetent virus was unable to induce expression of IP-10, the major determinant of IP-10 production is probably the tropism of the virus. Enteroviruses have been shown to infect several cell types in human islets, including beta cells and alpha cells [17, 37], strongly implicating these as potential sources of IP-10 production during enterovirus infection. However, contributions from other cell types such as islet endothelial cells cannot be excluded.

It seems very likely that the upregulation of IP-10 in vivo upon enterovirus infection of islets, would attract T-lymphocytes to the islets. This would contribute to insulitis and possibly to immune-mediated damage. Induction of IP-10 in the islets has been found to play an important role in the initiation of insulitis in the rat insulin promotor-lymphocytic choriomeningitis virus mouse model of virus-induced diabetes, where it leads to attraction of type 1 cytotoxic T-cells and T-helper-1 cells, natural killer cells and monocytes $[23,24]$.
In summary, this is the first study that has shown that infection of human islets with enterovirus can induce production and secretion of IP-10, a chemokine that plays a prominent role in the induction of insulitis and has also been detected at elevated concentrations in the serum of newly diagnosed type 1 diabetic patients and high-risk relatives [22]. Together, these findings provide additional support for the hypothesis that enterovirus infections might cause type 1 diabetes. Our results also provide a possible mechanism for explaining how enterovirus infections might trigger this disease.

Acknowledgements This study was supported by grants from the Gillbergska Foundation, the Ronald McDonald Fund, the Swedish Diabetes Foundation, the Family Ernfors Fund, Barndiabetesfonden and the Swedish Medical Research Council (K2006-32X-14035-06-3).

Duality of interest The authors are not aware of any duality of interest.

\section{References}

1. Christen U, Von Herrath MG (2004) IP-10 and type 1 diabetes: a question of time and location. Autoimmunity 37:273-282

2. Melnick JL (1990) Enteroviruses: polioviruses, coxsackie viruses, echo viruses, and newer enteroviruses. In: Fields BN (ed) Virology. Raven, New York, pp 549-605

3. Gamble DR, Taylor KW (1969) Seasonal incidence of diabetes mellitus. Br Med J 3:631-633

4. King ML, Shaikh A, Bidwell D, Voller A, Banatvala JE (1983) Coxsackie-B-virus-specific IgM responses in children with insulin-dependent (juvenile-onset; type I) diabetes mellitus. Lancet 1:1397-1399

5. Frisk G, Nilsson E, Tuvemo T, Friman G, Diderholm H (1992) The possible role of Coxsackie $\mathrm{A}$ and echo viruses in the pathogenesis of type I diabetes mellitus studied by IgM analysis. J Infect 24:13-22

6. Frisk G, Friman G, Tuvemo T, Fohlman J, Diderholm H (1992) Coxsackie B virus IgM in children at onset of type 1 (insulindependent) diabetes mellitus: evidence for IgM induction by a recent or current infection. Diabetologia 35:249-253

7. Yin H, Berg AK, Tuvemo T, Frisk G (2002) Enterovirus RNA is found in peripheral blood mononuclear cells in a majority of type 1 diabetic children at onset. Diabetes 51:1964-1971

8. Hyoty H, Hiltunen M, Knip M et al (1995) A prospective study of the role of coxsackie $\mathrm{B}$ and other enterovirus infections in the 
pathogenesis of IDDM. Childhood Diabetes in Finland (DiMe) Study Group. Diabetes 44:652-657

9. Hiltunen M, Hyoty H, Knip M et al (1997) Islet cell antibody seroconversion in children is temporally associated with enterovirus infections. Childhood Diabetes in Finland (DiMe) Study Group. J Infect Dis 175:554-560

10. Lonnrot M, Salminen K, Knip M et al (2000) Enterovirus RNA in serum is a risk factor for beta-cell autoimmunity and clinical type 1 diabetes: a prospective study. Childhood Diabetes in Finland (DiMe) Study Group. J Med Virol 61:214-220

11. Ylipaasto P, Klingel K, Lindberg AM et al (2004) Enterovirus infection in human pancreatic islet cells, islet tropism in vivo and receptor involvement in cultured islet beta cells. Diabetologia 47:225-239

12. Yoon JW, Austin M, Onodera T, Notkins AL (1979) Isolation of a virus from the pancreas of a child with diabetic ketoacidosis. N Engl J Med 300:1173-1179

13. Champsaur HF, Bottazzo GF, Bertrams J, Assan R, Bach C (1982) Virologic, immunologic, and genetic factors in insulin-dependent diabetes mellitus. J Pediatr 100:15-20

14. Frisk G, Diderholm H (2000) Tissue culture of isolated human pancreatic islets infected with different strains of coxsackievirus B4: assessment of virus replication and effects on islet morphology and insulin release. Int J Exp Diabetes Res 1:165-175

15. Roivainen M, Rasilainen S, Ylipaasto P et al (2000) Mechanisms of coxsackievirus-induced damage to human pancreatic beta-cells. J Clin Endocrinol Metab 85:432-440

16. Chehadeh W, Kerr-Conte J, Pattou F et al (2000) Persistent infection of human pancreatic islets by coxsackievirus $\mathrm{B}$ is associated with alpha interferon synthesis in beta cells. J Virol 74:10153-10164

17. Yin H, Berg AK, Westman J, Hellerstrom C, Frisk G (2002) Complete nucleotide sequence of a Coxsackievirus B-4 strain capable of establishing persistent infection in human pancreatic islet cells: effects on insulin release, proinsulin synthesis, and cell morphology. J Med Virol 68:544-557

18. Olsson A, Johansson U, Korsgren O, Frisk G (2005) Inflammatory gene expression in Coxsackievirus B-4-infected human islets of Langerhans. Biochem Biophys Res Commun 330:571-576

19. Ylipaasto P, Kutlu B, Rasilainen S et al (2005) Global profiling of coxsackievirus- and cytokine-induced gene expression in human pancreatic islets. Diabetologia 48:1510-1522

20. Baggiolini M, Dewald B, Moser B (1997) Human chemokines: an update. Annu Rev Immunol 15:675-705

21. Shimada A, Morimoto J, Kodama K et al (2001) Elevated serum IP-10 levels observed in type 1 diabetes. Diabetes Care 24:510-515

22. Nicoletti F, Conget I, Di Mauro M et al (2002) Serum concentrations of the interferon-gamma-inducible chemokine IP10/CXCL10 are augmented in both newly diagnosed Type I diabetes mellitus patients and subjects at risk of developing the disease. Diabetologia 45:1107-1110

23. Frigerio S, Junt T, Lu B et al (2002) Beta cells are responsible for CXCR3-mediated T-cell infiltration in insulitis. Nat Med 8:1414-1420
24. Christen U, McGavern DB, Luster AD, von Herrath $M G$, Oldstone MB (2003) Among CXCR3 chemokines, IFN-gammainducible protein of $10 \mathrm{kDa}$ (CXC chemokine ligand (CXCL) 10) but not monokine induced by IFN-gamma (CXCL9) imprints a pattern for the subsequent development of autoimmune disease. J Immunol 171:6838-6845

25. Ricordi C, Lacy PE, Scharp DW (1989) Automated islet isolation from human pancreas. Diabetes 38 (Suppl 1):140-142

26. Frisk G, Diderholm H (1997) Antibody responses to different strains of coxsackie B4 virus in patients with newly diagnosed type I diabetes mellitus or aseptic meningitis. J Infect 34:205210

27. Frisk G, Tuvemo T (2004) Enterovirus infections with beta-cell tropic strains are frequent in siblings of children diagnosed with type 1 diabetes children and in association with elevated levels of GAD65 antibodies. J Med Virol 73:450-459

28. Hartig PC, Madge GE, Webb SR (1983) Diversity within a human isolate of coxsackie B4: relationship to viral-induced diabetes. J Med Virol 11:23-30

29. Rozen S, Skaletsky HJ (2000) Primer3 on the WWW for general users and for biologist programmers. In: Krawetz S, Misener S (eds) Bioinformatics methods and protocols: Methods in molecular biology. Humana Press, Totowa, pp 365-386

30. Palma JP, Kim BS (2004) The scope and activation mechanisms of chemokine gene expression in primary astrocytes following infection with Theiler's virus. J Neuroimmunol 149:121-129

31. Spurrell JC, Wiehler S, Zaheer RS, Sanders SP, Proud D (2005) Human airway epithelial cells produce IP-10 (CXCL10) in vitro and in vivo upon rhinovirus infection. Am J Physiol Lung Cell Mol Physiol 289:L85-L95

32. Aminev AG, Amineva SP, Palmenberg AC (2003) Encephalomyocarditis viral protein $2 \mathrm{~A}$ localizes to nucleoli and inhibits capdependent mRNA translation. Virus Res 95:45-57

33. Doedens JR, Kirkegaard K (1995) Inhibition of cellular protein secretion by poliovirus proteins 2B and 3A. Embo J 14:894-907

34. Dodd DA, Giddings TH Jr, Kirkegaard K (2001) Poliovirus 3A protein limits interleukin-6 (IL-6), IL-8, and beta interferon secretion during viral infection. J Virol 75:8158-8165

35. Wessels E, Duijsings D, Notebaart RA, Melchers WJ, van Kuppeveld FJ (2005) A proline-rich region in the coxsackievirus $3 \mathrm{~A}$ protein is required for the protein to inhibit endoplasmic reticulum-to-golgi transport. J Virol 79:5163-5173

36. Cardozo AK, Proost P, Gysemans C, Chen MC, Mathieu C, Eizirik DL (2003) IL-1beta and IFN-gamma induce the expression of diverse chemokines and IL-15 in human and rat pancreatic islet cells, and in islets from pre-diabetic NOD mice. Diabetologia 46:255-266

37. Roivainen M, Ylipaasto P, Savolainen C, Galama J, Hovi T, Otonkoski T (2002) Functional impairment and killing of human beta cells by enteroviruses: the capacity is shared by a wide range of serotypes, but the extent is a characteristic of individual virus strains. Diabetologia 45:693-702 